\title{
UNA VISITA A HANS KELSEN EN MÉXICO
}

\author{
KELSEN IN MEXICO: A VISIT
}

Imer B. FLORES*

\begin{abstract}
Resumen:
Reflexionar sobre la influencia de Hans Kelsen en México obliga a recordar no solamente las visitas a México y de los mexicanos que fueron en su búsqueda, sino además las diferentes visiones que existen sobre él en México. Así, comenzamos con los viajes de Kelsen a México —desde el cancelado hasta el concretado, sin olvidar una infinidad de invitaciones para visitar el país; continuamos con las visitas de los mexicanos a Kelsen; y concluimos con una visita a Kelsen en México, donde revisamos la bibliohemerografia publicada de y sobre él en México o de autores mexicanos. Para tal efecto me permito hacer un breve recuento de las obras publicadas y de las polémicas que existen en torno al grado de influencia de su pensamiento - o fidelidad de los discípulos kelsenianos y hasta de los antikelsenianos respecto al mismo. Finalmente, incluimos una reflexión final sobre la trascendencia de su obra a partir de un par de anécdotas.
\end{abstract}


Esta revista forma parte del acervo de la Biblioteca Jurídica Virtual del Instituto de Investigaciones Jurídicas de la UNAM

IMER B. FLORES

\title{
Palabras clave:
}

Hans Kelsen, teoría pura del derecho, positivismo jurídico, recepción de la filosofía, México.

\begin{abstract}
:
Revisiting the influence of Hans Kelsen in Mexico requires a revision not only of his visits to Mexico and of the Mexicans to him, but also the different accounts of his thought that exist in Mexico. Hence, we commence by remembering his visits to Mexico - from the cancelled to the consummated, including a endless lists of invitations to visit the country; we continue with the visits of the Mexicans to Kelsen; and we conclude with a visit to Kelsen in Mexico, where we proceed to review the bibliography published both of and on him in Mexico or of Mexican authors. For that purpose, I will do a brief recount of his published works and of the existing debates regarding the extent of influence of his thought - or the fidelity of both kelsenians and antikelsenians. Finally, we include a final consideration on the trascendence of his work.
\end{abstract}

\section{Keywords:}

Hans Kelsen, Pure Theory of Law, Legal Positivism, Jurisprudential recepción, Mexico. 
La finalidad que en esta obra perseguimos y que, de entonces acá, informa también los demás trabajos de investigación emprendidos por nosotros, es la de llegar a una teoría pura del derecho como teoria del derecho positivo. Ya en esta primera obra nuestra nos esforzamos por asegurar la pureza de la teoría o - para decirlo en otros términos- la sustantividad del derecho en cuanto objeto de conocimiento científico, desde dos puntos de vista. De una parte, saliendo al paso de las pretensiones de la llamada consideración "sociológica", la cual trata de captar el derecho como un fragmento de la realidad natural, con ayuda del método científico-causal. De otra parte, enfrentándonos con la teoría del derecho natural, que -ignorando el fundamento de las relaciones, que se da única y exclusivamente en el derecho positivotrata de arrancar la teoría del derecho del campo de las normas jurídicas positivas para llevarla al terreno de los postulados ético políticos.

Hans Kelsen, "Prólogo a la segunda edición", Problemas capitales de la teoria jurídica del Estado (1923).

La Teoría pura del derecho constituye una teoría sobre el derecho positivo; se trata de una teoría sobre el derecho positivo en general, y no de una teoría sobre un orden jurídico específico. Es una doctrina general sobre el derecho, y no la interpretación de normas jurídicas particulares, nacionales o internacionales. Ofrece, sin embargo, también una teoría de la interpretación.

En cuanto teoría pretende, exclusiva y únicamente, discutir su objeto. Intenta dar respuesta a la pregunta de qué sea el derecho, y cómo sea; pero no, en cambio, a la pregunta de cómo el derecho deba ser o deba ser hecho. Es ciencia jurídica; no, en cambio, política jurídica.

Al caracterizarse como una "doctrina" pura con respecto del derecho, lo hace porque quiere obtener solamente un conocimiento orientado hacia el derecho, y porque desearia excluir de ese conocimiento lo que no pertenece al objeto precisamente determinado como jurídico. Vale decir: quiere liberar a la ciencia jurídica de todos los elementos que les son extraños. Hans Kelsen, Teoría pura del derecho (1960).

PROBLEMA

Anuario de Filosofía y Teoría del Derecho,

Núm. 8, enero-diciembre de 2014, pp. 53-94 
Esta revista forma parte del acervo de la Biblioteca Jurídica Virtual del Instituto de Investigaciones Jurídicas de la UNAM www.juridicas.unam.mx

http://biblio.juridicas.unam.mx

IMER B. FLORES

SumArio: I. Prólogo. II. La(s) visita(s) a México. III. La(s) visita(s) de los mexicanos. IV. La(s) visita(s) a Kelsen en México. V. Epílogo. VI. Referencias.

\section{PRÓlOGO}

Reflexionar sobre la influencia de Hans Kelsen en México obliga a recordar no solamente las visitas a México y de los mexicanos que fueron en su búsqueda, sino además las diferentes visiones que existen sobre él en México. Así, después de este brevísimo "Prólogo", comenzamos con los viajes de Kelsen a México -desde el cancelado hasta el concretado, sin olvidar una infinidad de invitaciones para visitar el país; continuamos con las visitas de los mexicanos a Kelsen; y concluimos con una visita a Kelsen en México, donde revisamos la bibliohemerografia publicada de y sobre él en México o de autores mexicanos. Finalmente, incluimos a manera de "Epílogo" una reflexión a partir de un par de anécdotas.

\section{LA(S) VISITA(S) A MÉXICO}

Cabe recordar que Hans Kelsen arribó al nuevo mundo, en el verano de 1940, ya que aceptó la invitación de Roscoe Pound para dictar en la Facultad de Derecho de la Universidad de Harvard las conferencias Oliver Wendell Holmes Jr. bajo el título de "El derecho y la paz en las relaciones internacionales". Ahora bien, en plena Segunda Guerra Mundial, en los Estados Unidos de América, le ofrecieron: primero, una plaza como investigador asociado (research associate) en derecho comparado en dicha Universidad para el año académico 1940-41, misma que fue extendida al 1941-42; y, luego, un nombramiento temporal como profesor visitante (visiting professor) en el Departamento de Ciencias Politicas de la Universidad de California en Berkeley 
Esta revista forma parte del acervo de la Biblioteca Jurídica Virtual del Instituto de Investigaciones Jurídicas de la UNAM www.juridicas.unam.mx

http://biblio.juridicas.unam.mx

UNA VISITA A HANS KELSEN EN MÉXICO

para el año académico 1942-43. ${ }^{1}$ Así, una vez en el continente americano fue invitado originalmente por Eduardo García Máynez y por el director de la hoy Facultad de Derecho, otrora Escuela Nacional de Jurisprudencia, Alfonso Noriega Jr. para impartir en los meses de enero y febrero de 1943 los "Cursos Extraordinarios de Invierno" en la Universidad Nacional Autónoma de México (UNAM). Aun cuando, ya estaban preparadas las conferencias que impartiria, por diferentes problemas en Berkeley, donde obtendria un nombramiento como profesor de tiempo completo (full-time professor) hasta 1945, esta visita a México se vio imposibilitada. No obstante, las dos conferencias que Kelsen dictaria y cuya publicación dedicaría a García Máynez aparecieron ese mismo año bajo el título de El contrato y el tratado. Analizados desde el punto de vista de la teoria pura del derecho. ${ }^{2}$ En palabras del propio Noriega: ${ }^{3}$

Desgraciadamente, causas ajenas a la voluntad del distinguido profesor austríaco le impidieron venir a nuestro país; pero, al excusarse de no poder asistir y expresar el agradecimiento que sentía, envió el texto original de dichas conferencias, que había redactado en francés; autorizó su publica-

1 Vid. Rudolf Aladár Métall, Hans Kelsen. Vida y obra, trad. de Javier Esquivel, México, UNAM, Instituto de Investigaciones Jurídicas, 1976, pp. 83-85. Vid. también Grant, J. A. C., "Semblanza", trad. de Guadalupe Ordóñez, Boletín Mexicano de Derecho Comparado, Nueva Serie, año VII, núm. 21, septiembre-diciembre de 1974, pp. 3-5; Víctor Alarcón Olguín, "Hans Kelsen: Bitácora de un itinerante", en Correas, Óscar (comp.), El otro Kelsen, México, UNAM, 1989, pp. 24-25; y Bayer, Kurt G., "Hans Kelsen. Vida y obra", Revista de la Facultad de Derecho, t. LV, núm. 244, 2005, pp. 231-232.

2 Vid. Kelsen, Hans, El contrato y el tratado. Analizados desde el punto de vista de la Teoría Pura del Derecho, trad. de Eduardo García Máynez, México, Imprenta Universitaria, 1943. Vid. también Alarcón Olguín, "Hans Kelsen...", cit., nota 1, p. 26. La dedicatoria del libro dice: "Dedico este estudio al profesor Eduardo García Máynez. H. K.”.

3 Noriega Jr., Alfonso, "Palabras preliminares", en Kelsen, cit., nota 2, p. X. 
Esta revista forma parte del acervo de la Biblioteca Jurídica Virtual del Instituto de Investigaciones Jurídicas de la UNAM www.juridicas.unam.mx

http://biblio.juridicas.unam.mx

IMER B. FLORES

ción, y dedicó la obra al eminente profesor de nuestra Universidad, licenciado Eduardo García Máynez.

Cabe mencionar que la Revista de la Escuela Nacional de Jurisprudencia, en el último número del año 1946, adelantaba los "Próximos cursos de invierno en los meses de enero y febrero de 1947" y entre ellos en primerísimo lugar anunciaba la presencia de Kelsen para dictar en inglés tres conferencias sobre "Las metamorfosis de la idea de justicia": ${ }^{4}$

Respecto de los cursos de invierno que habrán de tener lugar en los meses de enero y febrero del próximo año de 1947, podemos dar en firme la noticia de que en ellos participarán los siguientes profesores forasteros, cuyos servicios ha contratado ya la Escuela Nacional de Jurisprudencia: el Dr. Hans Kelsen, famoso creador de la "teoría pura del Derecho", ex profesor de las Universidades de Viena y Colonia, refugiado desde 1939 en los Estados Unidos, cuya ciudadanía se le ha otorgado, profesor huésped de la Universidad de Harvard y actualmente profesor de la Universidad de California...

Aun cuando, desconocemos porque tampoco se concretó esta visita que parecía estar "firme" resulta que en 1949 aparecería publicado en la misma Revista en español el artículo intitulado "Las metamorfosis de la idea de justicia" 5 correspondiente al artículo que Kelsen había preparado para una colección Interpretations of Modern Legal Philosophies. Essays in Honor of Roscoe Pound. Ahora bien, un par de años más tarde, el Consejo Universitario de la misma UNAM en la sesión extraordinaria del 27 de agosto de 1951 aprobó con motivo de su IV Centenario conceder al funda-

4 Vid. "Próximos cursos de invierno en los meses de enero y febrero de 1947", Revista de la Escuela Nacional de Jurisprudencia, t. VIII, núm. 32, octubre-diciembre de 1946, p. 373.

5 Vid. Hans Kelsen, "Las metamorfosis de la idea de justicia”, trad. de Óscar Morineau, Revista de la Escuela Nacional de Jurisprudencia, t. XI, núm. 44, octubre-diciembre de 1949, pp. 83-123. 
Esta revista forma parte del acervo de la Biblioteca Jurídica Virtual del Instituto de Investigaciones Jurídicas de la UNAM www.juridicas.unam.mx

http://biblio.juridicas.unam.mx

UNA VISITA A HANS KELSEN EN MÉXICO

dor de la Escuela Vienesa el grado de doctor honoris causa. ${ }^{6}$ Con posterioridad, Kelsen fue invitado por Emilio O. Rabasa, con el apoyo de Ricardo García Villalobos, director de la Facultad de Derecho, y de Nabor Carrillo Flores, rector de la Universidad, con la idea de "impartir una serie de conferencias que sintetizaran su muy conocida Teoria Pura del Derecho",7 intituladas "Algunos aspectos de la Teoría Pura del Derecho", en 1960, precisamente el mismo año en que aparecería la segunda edición, revisada y definitiva, de la Reine Rechtslehre, misma que traía bajo el brazo a su llegada a México.

Como es sabido, la visita es célebre por infinidad de razones; entre ellas, se suelen citar, en primerísimo lugar, el hecho de que cuando Kelsen apareció para dictar la primera conferencia en la Biblioteca Antonio Caso de la Facultad de Derecho de la UNAM, el espacio previsto resultó totalmente insuficiente dada la gran expectativa que había generado la concreción por fin de su tan esperada visita y su conferencia tuvo que llevarse a cabo en el Paraninfo de la Facultad de Medicina. En voz del propio Rabasa: ${ }^{8}$

El 30 de marzo de 1960, exactamente a las 7 p.m., un pequeño hombre se adentró en la Ciudad Universitaria de México. Una inquieta y emocionada multitud de más de tres mil personas le aguardaba en la Facultad de Derecho, con la ex-

6 Vid. Métall, Hans Kelsen..., cit., nota 1. 103. No obstante, hay alguna discrepancia respecto a este dato pues algún otro autor lo ha fechado el 21 de julio de 1951. Cfr. Rolando Tamayo y Salmorán, "Hans Kelsen. In memoriam", Boletín Mexicano de Derecho Comparado, año VII, núm. 19, enero-abril de 1974, p. XIII. Estamos convencidos que la fecha correcta es la de agosto y para tal efecto baste citar: Alicia Alarcón, El Consejo Universitario. Sesiones de 1924-1977, México, UNAM, 1979, t. I, p. 270.

7 Rabasa, Emilio O., "Nota liminar a la segunda edición peruana", en Kelsen, Hans, Introducción a la Teoría Pura del Derecho, trad. de Emilio O. Rabasa, Lima, Asociación Peruana de Derecho Constitucional, 2001, p. 13.

8 Rabasa, Emilio O., "Prólogo", en Kelsen, Hans, Introducción a la Teoría Pura del Derecho, trad. de Emilio O. Rabasa, México, UNAM, Facultad de Derecho, 1960, pp. 7-9. 
pectación y respeto sólo reservados para los grandes hombres. Y es que, en realidad, se trataba de un gran hombre...

Añeja preocupación había sido de la Facultad de Derecho de la Universidad Nacional Autónoma de México el traer al llamado Jefe de la Escuela Vienesa, cuyo pensamiento era abordado en las más asignaturas de ese Centro de Estudios, ora para explicar algún problema de Teoría General del Estado, ora para desarrollar algún matiz de Introducción al Derecho, unas veces para criticar al maestro y lograr bases para una nueva doctrina, otras para fundar una concepción jurídica total, pero siempre considerándole como punto de referencia de la exposición. Anti o pro-kelsenianos, todos estaban acordes en atraer a nuestras aulas al eminente jurista para escuchar directamente, sin intérprete y sin crítico, la esencia de su teoría esencial...

Arribó Kelsen y la Universidad fue digna de él, así como el profesor fue digno de nuestra Casa de Estudios. Los profesores, alumnos, juristas, hombres de ciencia en general, y aún simples curiosos, que asistieron a la primera conferencia, vieron hacer e hicieron historia en la Universidad, cuando se congregaron para observar y escuchar a Hans Kelsen con la emoción y en el número hasta ahora nunca registrados en nuestra Casa de Estudios. Las visitas de profesores y alumnos, los honores dispensados al ilustre visitante... materializaron el principio de que a los grandes hombres de ciencia, nacionales o extranjeros, México sabe rendirles adecuado tributo.

Cabe señalar que el sombrero de Kelsen se perdió tras la tumultuosa recepción y procesión hasta la Facultad de Medicina, pues al parecer lo dejó en la Facultad de Derecho y a su regresó ya no lo encontró. ${ }^{9}$ Como cuenta Rabasa: "La visita resultó realmente inolvidable y fue atendido por las más altas autoridades universitarias y gubernamentales de

9 La anécdota del sombrero se la he escuchado varias veces a Luis J. Molina Piñeiro, quien la escuchó a su vez del mismísimo Luis Recaséns Siches, quien le sugirió a Kelsen que alguien se lo había llevado como un "recuerdo" de su visita. 
Esta revista forma parte del acervo de la Biblioteca Jurídica Virtual del Instituto de Investigaciones Jurídicas de la UNAM www.juridicas.unam.mx

http://biblio.juridicas.unam.mx

UNA VISITA A HANS KELSEN EN MÉXICO

México", 10 incluido el entonces Presidente de la República: Adolfo López Mateos. Así mismo, como explica Rabasa: ${ }^{11}$

Proyectadas cuatro conferencias y algunos otros actos para que el maestro conviviera directa y espontáneamente con profesores y alumnos, desafortunadamente un quebranto en su salud evitó la conclusión de todo el programa. Sin embargo, y queriendo dejar sentado su paso por nuestro país y nuestra Universidad, como recuerdo perene de su visita, envió al suscrito, en inglés, una "Introducción" a su celebérrima "Teoría Pura del Derecho", para su traducción y publicación.

El principal producto de esta visita fue la publicación en ese mismo año de la Introducción a la Teoría Pura del Derecho. ${ }^{12}$ Aunado a lo anterior, en el marco de la misma, Kelsen se convirtió el 5 de abril de 1960 en "profesor extraordinario" de la Facultad de Derecho de la UNAM y fue nombrado tanto "miembro correspondiente" del otrora Instituto de Derecho Comparado, ahora Instituto de Investigaciones Jurídicas, de la UNAM, ${ }^{13}$ como "miembro honorario" de la Sociedad Mexicana de Filosofia. ${ }^{14}$ Como dato curioso, en una comida en la Fonda Santa Anita, José Luis Curiel B. en nombre de dicha Sociedad propondría a "Kelsen como candidato a recibir el Premio Nobel de la Paz". ${ }^{15}$

10 Rabasa, "Nota liminar...", cit., nota 7, p. 13.

11 Rabasa, "Prólogo", cit., nota 8, p. 9. Aún cuando se popularizó la creencia de que había sido la comida mexicana la causante de tal quebranto - y hasta algún mal gesto- resulta que Kelsen, quien en aquel entonces tenía casi ochenta años, no solamente se comprometía mucho al hablar sino que además contrajo una afección de las vías respiratorias, lo cual aunado a la prescripción de su médico de tener cuidado con la altura de la ciudad de México precipitaron su regreso a Berkeley.

12 Vid. Kelsen, Introducción a la teoría pura del derecho, cit., nota 8.

13 Vid. Métall, Hans Kelsen..., cit., nota 1, pp. 103-104. Vid. también Tamayo y Salmorán, "Hans Kelsen...", cit., nota 6, p. XIII; y vid. Boletín del Instituto de Derecho Comparado de México, año XIII, núm. 37, enero-abril de 1960, p. 285.

14 Vid. Métall, Hans Kelsen..., cit., nota 1, p. 104.

15 Alarcón Olguín, "Hans Kelsen...", cit., nota 1, p. 26. 
Esta revista forma parte del acervo de la Biblioteca Jurídica Virtual del Instituto de Investigaciones Jurídicas de la UNAM www.juridicas.unam.mx

http://biblio.juridicas.unam.mx

IMER B. FLORES

Kelsen sería invitado a visitar México en al menos una ocasión más para asistir a un homenaje en la Facultad de Derecho de la UNAM con motivo del nonagésimo aniversario de su natalicio el 14 de octubre de 1971. ${ }^{16}$ Sin embargo, como es fácil de suponer, a Kelsen por su avanzada edad le fue imposible aceptar la invitación que le formularon Fernando Ojesto Martínez, director de la Facultad, y Rafael Preciado Hernández, presidente del Colegio de Profesores de Filosofia del Derecho e Introducción al Estudio del Derecho. La invitación en papel con el sello de la Dirección de la Facultad de Derecho y con el escudo de la UNAM: ${ }^{17}$

Sr. Profesor Hans Kelsen,

21 de septiembre de 1971

Presente, Ilustre Profesor:

Nos complace profundamente comunicarle que el Colegio de Profesores de Filosofia del Derecho e Introducción al Estudio del Derecho de esta Facultad, acordó celebrar el 14 de octubre de este año, en ocasión del Aniversario de su Nacimiento, un acto público de homenaje a usted por su importante obra realizada en el campo de la Teoría del Derecho y del Estado y como fundador de la Escuela de Viena, e invitarlo cordialmente para que asista a dicho acto.

Le rogamos, pues, que si le es posible esto último, se sirva avisarnos en breve lapso para atender lo relativo a los gastos de su viaje y estancia en esta ciudad.

Reciba nuestro respetuoso saludo.

Atentamente.

"POR MI RAZA HABLARÁ EL ESPÍRITU”

EL DIRECTOR DE LA FACULTAD

Lic. Fernando Ojesto Martínez

EL PRESIDENTE DEL COLEGIO

Lic. Rafael Preciado Hernández

16 Vid. "Homenaje al profesor Hans Kelsen", Revista de la Facultad de Derecho de México, t. XXII, núms. 85-86, enero-junio de 1972, pp. 317 y ss.

17 Ibidem, p. 318. 
Esta revista forma parte del acervo de la Biblioteca Jurídica Virtual del Instituto de Investigaciones Jurídicas de la UNAM www.juridicas.unam.mx

http://biblio.juridicas.unam.mx

UNA VISITA A HANS KELSEN EN MÉXICO

Su respuesta, a su vez, en papel con el sello del Department of Political Science de la University of California, Berkeley: 18

El director de la Facultad

September 24, 1971

Mr. Fernando Ojesto Martinez

El Presidente del Colegio

Mr. Rafael Preciado Hernández

National University of Mexico, Mexico City

Dear Sirs:

Please accept my cordial thanks for your kind letter of September twenty-first. I would be delighted to accept your kind invitation but, unfortunately, the weakness of old age confines me to my home.

I regret this all the more as my stay at your beautiful National University, in 1960, inspired me with the highest regard for the Faculty, and the response of the students also encouraged me greatly.

Be assured of my appreciation of the great honor you accord me and my feelings of sincere gratitude.

With my warmest wishes.

Sincerely yours,

Hans Kelsen

Cabe señalar que el "Homenaje al profesor Hans Kelsen" se llevó a cabo en la velada del 14 de octubre como estaba prevista y que en ella participaron varios profesores, cuyas intervenciones fueron publicadas en la Revista de la Facultad de Derecho de México: Leandro Azuara Pérez, ${ }^{19}$ Javier

18 Ibidem, p. 319.

19 Vid. Azuara Pérez, Leandro, "Investigaciones sociológicas de Hans Kelsen”, en loc. cit. en la nota 16, pp. 330-334. 
Esta revista forma parte del acervo de la Biblioteca Jurídica Virtual del Instituto de Investigaciones Jurídicas de la UNAM www.juridicas.unam.mx

http://biblio.juridicas.unam.mx

IMER B. FLORES

Esquivel, ${ }^{20}$ Agustín Pérez Carrillo, ${ }^{21}$ Ulises Schmill Ordóñez ${ }^{22}$ y Fausto E. Vallado Berrón. ${ }^{23}$

III. LA(S) VISITA(S) DE LOS MEXICANOS

Durante su estadía en México, Hans Kelsen tuvo la ocasión de reunirse con varios profesores y alumnos, entre ellos con el entonces recién graduado Ulises Schmill Ordónez ${ }^{24}$ quien le obsequió a su llegada al aeropuerto - donde lo recibieron Ricardo García Villalobos, Emilio O. Rabasa y Luis Recaséns Siches, entre otros- un ejemplar de su tesis que presentó para obtener el grado de Licenciado en Derecho por la Facultad de Derecho de la UNAM y que llevaba precisamente el título de El problema de la soberanía (1959) en clara alusión al largo ensayo de 1920: Das Problem der Souveränität und die Theorie des Völkerrechts. Al día siguiente, Schmill visitó a Kelsen en el Hotel Presidente, antes de que diera inicio la conferencia de prensa que se tenía prevista, para discutir diversos aspectos sobre su tesis y disipar algunas dudas sobre el pensamiento kelseniano. A esta primera visita siguieron algunos intercambios en el marco de los diferentes actos públicos y privados que se llevaron a cabo, incluida la comida en la Fonda Santa Anita. Al grado que Schmill pudo acordar con Kelsen una segunda visita, en la cual iría acompañado de los profesores Leandro Azuara Pérez y Fausto E. Vallado Berrón, quienes habían formado parte de su sínodo y querian — como eran adeptos

20 Vid. Esquivel, Javier, "Datos biográficos de Hans Kelsen”, en loc. cit. en la nota 16, pp. 320-324.

21 Vid. Pérez Carrillo, Agustín, "Ideas de Hans Kelsen respecto a la teoría de los valores", en loc. cit. en la nota 16, pp. 324-328.

22 Vid. Schmill Ordóñez, Ulises, "El Estado y el derecho internacional en la teoría pura del derecho", en loc. cit. en la nota 16, pp. 334-340.

23 Vid. Vallado Berrón, Fausto E., "La teoría pura del derecho (Concepto de la ciencia jurídica)", en loc. cit. en la nota 16, pp. 328-330.

24 Este apartado es producto en buena medida de la "Entrevista" que sostuve con Ulises Schmill Ordóñez en su cubículo del Instituto Tecnológico Autónomo de México (ITAM) el 23 de febrero de 2012. 
Esta revista forma parte del acervo de la Biblioteca Jurídica Virtual del Instituto de Investigaciones Jurídicas de la UNAM www.juridicas.unam.mx

http://biblio.juridicas.unam.mx

UNA VISITA A HANS KELSEN EN MÉXICO

al pensamiento del jefe de la Wiener Schule- conocer en persona al maestro.

Como es sabido, el 21 de abril de 1967, Schmill tuvo la oportunidad de visitar nuevamente a Kelsen, pero en esta ocasión en su casita ubicada en el número 2126 de Los Angeles Avenue, en Berkeley, California. ${ }^{25}$ Al respecto, después de varias horas de un fecundo y fraterno intercambio de opiniones sobre varios temas de la Teoría del Derecho, en general, y de la Teoría Pura del Derecho, en particular, el más conspicuo jurista del siglo XX — como narra el mismo Schmill- tenía deseos de citar un verso en alemán que él había escrito y que sería traducido al español para la posterioridad por el propio Schmill. El poema es una clara muestra de otra faceta de Kelsen hasta entonces desconocida: ${ }^{26}$

\section{Carpe Diem}

Bald, Ach Bald wirst du erblassen, Pronto, Oh! Pronto tu empalidecerás,

Diese schöne Welt verlassen Dejarás este bello mundo

Und vergessen sein. Y serás olvidado.

Darum sollst du dich nicht sorgen; Por ello no debes preocuparte;

Stets ist Heute, nie ist Morgen; $\quad$ Siempre es hoy, nunca es mañana;

Zeit ist Schein. $\quad$ El tiempo es ilusión.

Alzlzufernes nicht ertäumen, No ensueñes lo muy lejano,

Dich kann naher Glück verräumen. Puedes dar lugar a dichas cercanas.

Nur was du ergreifst ist dein! ¡Sólo lo que tomas es tuyo!

25 Schmill Ordóñez, Ulises, "Un poema de Hans Kelsen”, Doxa. Cuadernos de Filosofía del Derecho, núm. 19, 1996, p. 33-36.

26 Ibidem, p. 35. 
Esta revista forma parte del acervo de la Biblioteca Jurídica Virtual del Instituto de Investigaciones Jurídicas de la UNAM www.juridicas.unam.mx

http://biblio.juridicas.unam.mx

IMER B. FLORES

Ahora bien, como recuerda Schmill, Kelsen fue visitado en Berkeley con anterioridad a él por Guillermo Héctor Rodríguez en la década de los cincuenta, quien entre otras cosas le comentó que Kelsen lo llevó en su Oldsmobile a gran velocidad al aeropuerto, ${ }^{27}$ y con posterioridad a él por Guillermo Floris Margadant, quien le contó que Kelsen trabajaba en la Teoría general de la norma. Así mismo, Schmill - acompañado por Francisco Martín Moreno y Emilio Rabasa Gamboa - regresó a Berkeley para buscar a Kelsen poco antes de su muerte, pero por el deteriorado estado de salud ya no se pudo concretar la visita. Sin embargo, como recuerdo recibió un retrato de manos de su esposa: Margaret Kelsen.

Por cierto, en 1971, la Comisión Organizadora del Homenaje al doctor Eduardo García Máynez, se dirigió al ilustre profesor, e inclusive uno de sus miembros el doctor Flores García "[lo] visitó personalmente... para rogarle insistentemente su participación”. ${ }^{28}$ Al respecto, Kelsen escribió sendas cartas para ofrecer sus disculpas. Ambas en papel con el sello del Department of Political Science de la University of California, Berkeley. La primera por sí mismo:29

Dr. Fernando Flores García

19th. of July, 1971

Revista de la Facultad de Derecho de México

Mexico, City

Dear Sirs:

\footnotetext{
27 Suponemos que sin violar ni mucho menos violentar norma alguna y siempre dentro del "marco" interpretativo de la misma, pues cuando Emilio O. Rabasa cometió alguna infracción - muy probablemente por estar nervioso- mientras conducía su automóvil con Kelsen abordo. Éste le inquirió: “¿No se ha dado cuenta que ha violado una norma?” Esta anécdota creo recordar que se la escuché originalmente al propio Emilio O. Rabasa, pero también se la he escuchado a su hijo Emilio Rabasa Gamboa, colega en el Instituto de Investigaciones Jurídicas, y a Ulises Schmill Ordóñez.

28 "Cartas del doctor Hans Kelsen", Revista de la Facultad de Derecho de México, t. XXII, núms. 87-88, julio-diciembre de 1972, p. 587.

29 Ibidem, p. 588.
}

PROBLEMA

Anuario de Filosofia y Teoría del Derecho, Núm. 8, enero-diciembre de 2014, pp. 53-94 
Many thanks for your letter of June 21th., to my greatest regret I am not in a position to accept your invitation to contribute an essay to the volume in honor of Professor Dr. Eduardo García Máynez. I have no suitable article ready and, in view of my age, shall not be able to write one during the summer.

May I ask you to transmit to Professor Garcia Máynez my kindest personal regards and the expression of my highest esteem.

Sincerely

Hans Kelsen

Y la segunda por conducto de su esposa: ${ }^{30}$

Dr. Fernando Flores García

August 25, 1971

Facultad de Derecho

Universidad Nacional, México

México, City

Dear Sir:

My husband directed me to reply to your kind letter of August 5th., because he has not been well these weeks and is under strict orders for complete rest.

He is extremely sorry that, therefore, he cannot fulfill your wish concerning for the volume in honor of Dr. Eduardo García Máynez.

He sends you his best personal regards and excuses.

Sincerely

Margaret Kelsen

\section{LA(S) VISITA(S) A KeLSEn En MÉXico}

Para proceder a visitar las diferentes visiones que existen de Kelsen en México, me permito hacer un breve recuento no solamente de las obras publicadas de y sobre él tanto en ediciones originales como en reimpresiones sino además de la polémicas que existen en torno al grado de influencia de su pensamiento -0 mejor dicho de fidelidad de los discipulos kelsenianos y hasta de los antikelsenianos respecto al mismo.

30 Ibidem, p. 587. 
Esta revista forma parte del acervo de la Biblioteca Jurídica Virtual del Instituto de Investigaciones Jurídicas de la UNAM www.juridicas.unam.mx

http://biblio.juridicas.unam.mx

IMER B. FLORES

\section{Publicaciones de y sobre Kelsen en México}

Por una parte, está fuera de discusión que la extensa y vasta producción de Kelsen ha sido ampliamente traducida al español y lo más representativo de su pensamiento publicado en ediciones originales e inclusive en reimpresiones en México. ${ }^{31}$ Así, de un lado, entre las ediciones originales despuntan las traducciones que sus divulgadores tanto de origen mexicano como que en su momento radicaban en el pais hicieron:

Eduardo García Máynez tradujo del francés el manuscrito El contrato y el tratado. Analizados desde el punto de vista de la teoría pura del derecho; ${ }^{32}$ del inglés el libro General Theory of Law and State;33 y del alemán el manuscrito "Teoría pura y teoría egológica. Respuesta al artículo de Carlos Cossio: Teoría Egológica y Teoría Pura (Balance provisional de la visita de Kelsen a la Argentina)";34

Florencio Acosta tradujo del inglés las conferencias que Kelsen había dictado en la Facultad de Derecho de la Universidad de Harvard y que fueron publicadas bajo el título

31 Vid. Palomino Manchego, José F., "Bio-bibliografia de Hans Kelsen", en Kelsen, Introducción a la teoría pura del derecho, cit., nota 8, pp. 135-140.

32 Vid. Kelsen, El contrato y el tratado..., cit., nota 2.

33 Vid. Kelsen, Hans, Teoría general del derecho y del Estado, trad. de Eduardo García Máynez, México, Imprenta Universitaria, 1949.

34 Vid. Kelsen, Hans, "Teoría pura y teoría egológica. Respuesta al artículo de Carlos Cossio: Teoría Egológica y Teoria Pura (Balance provisional de la visita de Kelsen a la Argentina)", trad. de Eduardo García Máynez, Revista de la Facultad de Derecho de México, t. III, núm. 10, abril-junio de 1953, pp. 169-206. En la nota a pie de página identificada como 1, Eduardo García Máynez en su calidad de traductor revela el origen del texto: "La respuesta del Dr. Kelsen me fue enviada por él con la petición de que la tradujese al español y gestionase que se publicara en la Revista de la Facultad de Derecho de México". Vid. ibidem, p. 169. La razón es que el texto original había aparecido en esa misma Revista: Vid. Cossio, Carlos, "Teoría Egológica y Teoría Pura (Balance provisional de la visita de Kelsen a la Argentina)", Revista de la Facultad de Derecho de México, t. XII, núm. 45, enero-marzo de 1950, pp. 121-174.

PROBLEMA

Anuario de Filosofia y Teoría del Derecho, Núm. 8, enero-diciembre de 2014, pp. 53-94 
Esta revista forma parte del acervo de la Biblioteca Jurídica Virtual del Instituto de Investigaciones Jurídicas de la UNAM www.juridicas.unam.mx

http://biblio.juridicas.unam.mx

UNA VISITA A HANS KELSEN EN MÉXICO

de Law and Peace in International Relations: The Oliver Wendell Holmes Lectures 1940-41;35

Enrique Ferrer Vieyra tradujo del inglés el artículo "El principio de igualdad de soberanía entre los Estados, como base de la organización" para la sección de "Cultura Jurídica" de la revista La justicia que aparecería en marzo de $1946^{36}$ y se volvería a publicar en abril de $1947 ;^{37}$

Óscar Morineau tradujo del inglés el artículo "The Metamorphoses of the Idea of Justice"; 38

Emilio O. Rabasa tradujo del inglés los apuntes de las conferencias que dictaría Kelsen con motivo de su célebre visita a México;39

Mario de la Cueva tradujo del alemán el artículo "Was ist Juristischer Positivismus?";40

35 Vid. Kelsen, Hans, Derecho y paz en las relaciones internacionales, trad. de Florencio Acosta, México, Fondo de Cultura Económica, 1943.

36 Vid. Kelsen, Hans, "El principio de igualdad de soberanía entre los Estados como base de la organización internacional”, trad. de Enrique Ferrer Vieyra, La justicia, año XVI, t. XVI, núm. 223, marzo de 1946, pp. 8026-33. Una nota al pie de página de la redacción destaca: "Es para "Cultura Jurídica" motivo de especial complacencia publicar el presente trabajo del eminente profesor Hans Kelsen, quien se lo entregó, con tal finalidad, personalmente a nuestro Director durante su reciente visita a Norte América. La traducción se debe al Doctor Enrique Ferrer Vieyra, becario de la Universidad de Berkeley y discipulo de Kelsen. Por la actualidad del tema y por la autoridad internacional y gran prestigio del autor, no dudamos en afirmar que las ideas de Kelsen representan un aporte valioso al planteamiento del orden jurídico internacional de la post-guerra".

37 Kelsen, Hans, "El principio de igualdad de soberanía entre los Estados como base de la organización internacional", trad. de Enrique Ferrer Vieyra, La justicia, año XVII, t. XVI, núm. 236, abril de 1947, pp. 89338941. El texto incluye una nota a pie de página que al parecer fue omitida en la versión anterior, cfr. Kelsen, supra nota 35.

38 Vid. Kelsen, "Las metamorfosis de la idea de justicia", cit., nota 5.

39 Vid. Kelsen, Introducción a la teoría pura del derecho, cit., nota 8.

40 Vid. Kelsen, Hans, “¿Qué es el positivismo jurídico?”, trad. de Mario de la Cueva, Revista de la Facultad de Derecho de México, t. XVI, núm. 61, enero-marzo de 1966, pp. 131-143. 
Esta revista forma parte del acervo de la Biblioteca Jurídica Virtual del Instituto de Investigaciones Jurídicas de la UNAM www.juridicas.unam.mx

http://biblio.juridicas.unam.mx

IMER B. FLORES

Leandro Azuara Pérez tradujo del alemán el ensayo "Der soziologische und der juristische staatsbegriff, kritische untersuchung des verhältnisses von staat und recht"; 41

Federico Weber tradujo del alemán el ensayo "Die Grundlage der Naturrechtslehre";42

Rolando Tamayo y Salmorán tradujo — tras la muerte de Kelsen- del francés el opúsculo La garantie jurisdictionelle de la Constitution. (La justice constitutionnelle); 43

Ulises Schmill Ordóñez y Jorge Castro Valle tradujeron del alemán el artículo "Recht und Logik", ${ }^{44}$ y el mismo Schmill Ordóñez el artículo "Was ist ein Rechtsakt?";45

Roberto J. Vernengo tradujo del alemán, la segunda edición revisada y definitiva de Reine Rechstlehre. Mit einem anhang: Das Problem der Gerechtigkeit; ${ }^{46}$

41 Vid. Kelsen, Hans, "Sobre los límites entre el método sociológico y el jurídico", trad. de Leandro Azuara Pérez, Revista de la Facultad de Derecho de México, t. XIX, núms. 75-76, julio-diciembre de 1969, pp. 169-205.

42 Vid. Kelsen, Hans, "La fundamentación de la doctrina del derecho natural", trad. de Federico Weber, Juridica. Anuario del Departamento de Derecho de la Universidad Iberoamericana, t. II, núm. 2, 1970, pp. 247290. El artículo viene antecedido por un facsímil de una carta en alemán escrita de puño y letra por Kelsen dirigida a Manuel Borja Martínez, a la sazón Director de la Escuela de Derecho de la Universidad Iberoamericana, para autorizar la publicación de la traducción al español de su artículo.

43 Vid. Hans Kelsen, "La garantía jurisdiccional de la constitución. (La justicia constitucional)", trad. de R. Tamayo y Salmorán, Anuario Jurídico, núm. 1, 1974, pp. 469-515. El Anuario Jurídico contiene la siguiente nota: "Al tener conocimiento del fallecimiento de Hans Kelsen, quien fuera el más grande jurista de nuestro tiempo, el Instituto de Investigaciones Jurídicas ha querido rendirle un pequeño homenaje en este Anuario Jurídico, incluyendo, en la sección de clásicos, uno de los más importantes trabajos del genio fundador de la Escuela de Viena". Ibidem, p. 9.

44 Vid. Kelsen, Hans, "Derecho y lógica", Cuadernos de Crítica, México, UNAM, Instituto de Investigaciones Filosóficas, núm. 6, 1978.

45 Vid. Kelsen, Hans, "Qué es un acto jurídico?", trad. de Ulises Schmill Ordóñez, Isonomía. Revista de Teoría y Filosofía del Derecho, México, núm. 4, abril de 1996, pp. 65-76.

46 Vid. Kelsen, Hans, Teoría pura del derecho, trad. de Roberto J. Vernengo, México, UNAM, 1979. 
Esta revista forma parte del acervo de la Biblioteca Jurídica Virtual del Instituto de Investigaciones Jurídicas de la UNAM www.juridicas.unam.mx

http://biblio.juridicas.unam.mx

UNA VISITA A HANS KELSEN EN MÉXICO

Alfonso García Ruiz tradujo del alemán Sozialismus und Staat. Eine Umersuchung der politíschen Theoríe des Marxismus; ${ }^{47}$

Wenceslao Roces tradujo del alemán, la segunda edición revisada y definitiva de Hauptprobleme der Staatsrechtslehre. Entwickelt aus der Lehre vom Rechtssatze; ${ }^{48}$ y

Hugo Carlos Delory Jacobs tradujo del alemán la obra póstuma Allgemeine Theorie der Norme. 49

Del otro, entre las reimpresiones que se han publicado en México destacan: La teoría pura del derecho. Método y conceptos fundamentales; ${ }^{50}$ Esencia $y$ valor de la democracia; ${ }^{51}$

47 Vid. Kelsen, Hans, Socialismo y Estado. (Una investigación sobre la teoría politica del marxismo), trad. de Alfonso García Ruíz, México, Siglo XXI Editores, 1982.

48 Vid. Kelsen, Hans, Problemas capitales de la teoría jurídica del Estado (Desarrollados con base en la doctrina de la proposición jurídica), trad. de Wenceslao Roces, México, Porrúa-UNAM, Instituto de Investigaciones Jurídicas, 1987. La traducción de esta obra fue encargada por Manuel Gual Vidal, secretario de Educación Pública, durante la presidencia de Miguel Alemán Valdés (1946-1952), a Wenceslao Roces a instancias de Guillermo Héctor Rodríguez y estuvo guardada por muchos años hasta que éste regaló la misma a Ulises Schmill Ordóñez, quien —cuando era ministro de la Suprema Corte de Justicia de la Nación- procedió a acordar su publicación por la UNAM con la siguiente dedicatoria: "La Universidad Nacional Autónoma de México dedica la publicación de esta obra de Hans Kelsen al profesor Guillermo Héctor Rodríguez, expositor en México de la teoría pura del derecho, por su brillante labor docente por más de 30 años".

49 Vid. Kelsen, Hans, Teoría general de las normas, trad. de Hugo Carlos Delory Jacobs, México, Trillas, 1994. Aunque esta edición fue autorizada por el Hans Kelsen-Institut, tengo entendido que Carla Huerta, colega en el Instituto de Investigaciones Jurídicas de la UNAM, también bajo el auspicio del Hans Kelsen-Institut prepara otra versión con una traducción suya.

50 Vid. Kelsen, Hans, La Teoría Pura del Derecho. Método y conceptos fundamentales, trad. de Luis Legaz y Lacambra, México, Colofón, 1989.

51 Vid. Kelsen, Hans, Esencia y valor de la democracia, trad. de Luis Luengo Tapia y Luis Legaz y Lacambra, México, Editora Nacional, 1974. 
Esta revista forma parte del acervo de la Biblioteca Jurídica Virtual del Instituto de Investigaciones Jurídicas de la UNAM www.juridicas.unam.mx

http://biblio.juridicas.unam.mx

IMER B. FLORES

Compendio de Teoria General del Estado;52 Teoria General del Estado; 53 La Teoría Pura del Derecho. Introducción a la problemática cientifica del derecho; 54 La idea del derecho natural y otros ensayos; 55 ¿Qué es la justicia?; 56 ¿Qué es la Teoría Pura del Derecho?; 57 y Contribuciones a la Teoría Pura del Derecho. 58

Aunado a todas las obras anteriores, habría que mencionar que al tener conocimiento de la muerte de Kelsen, Rolando Tamayo y Salmorán en aquel entonces, además de investigador, Secretario del Instituto de Investigaciones Jurídicas de la UNAM, se dio a la tarea de compilar y dirigir un número especial "Estudios en memoria de Hans Kelsen" del Boletín Mexicano de Derecho Comparado. ${ }^{59}$ Cabe aclarar que el homenaje comprendió dos volúmenes: el número especial identificado como 19 y además el número 21.60

52 Vid. Kelsen, Hans, Compendio de Teoría General del Estado, trad. de Luis Recaséns Siches y Justino de Azcárate, México, Editora Nacional, 1980.

53 Vid. Kelsen, Hans, Teoría General del Estado, trad. de Luis Legaz y Lacambra, México, Editora Nacional, 1965.

54 Vid. Kelsen, Hans, La Teoría Pura del Derecho. Introducción a la problemática científica del derecho, trad. de Jorge G. Tejerina, México, Editora Nacional, 1981.

55 Vid. Kelsen, Hans, La idea del derecho natural y otros ensayos, trad. de Francisco Ayala et al., México, Editora Nacional, 1974.

56 Vid. Kelsen, Hans, ¿Qué es la justicia?, trad. de Ernesto Garzón Valdés, México, Distribuciones Fontamara, 1991.

57 Vid. Kelsen, Hans, ¿Qué es la Teoría Pura del Derecho?, trad. de Ernesto Garzón Valdés, México, Distribuciones Fontamara, 1991.

58 Vid. Kelsen, Hans, Contribuciones a la Teoría Pura del Derecho, trad. de Eduardo A. Vásquez, México, Distribuciones Fontamara, 1991.

59 Vid. Boletín Mexicano de Derecho Comparado, nueva serie, año VII, núm. 19, enero-abril de 1974.

60 Vid. Boletín Mexicano de Derecho Comparado, nueva serie, año VII, núm. 21, septiembre-diciembre de 1974 . 
Esta revista forma parte del acervo de la Biblioteca Jurídica Virtual del Instituto de Investigaciones Jurídicas de la UNAM www.juridicas.unam.mx

http://biblio.juridicas.unam.mx

UNA VISITA A HANS KELSEN EN MÉXICO

Por un lado, el primero incluyó no sólo artículos de Javier Esquivel, ${ }^{61}$ Luis Recaséns Siches ${ }^{62}$ y del propio Rolando Tamayo y Salmorán, ${ }^{63}$ entre otros autores de fama mundial, quienes hacen referencia expresa a la obra y a la influencia del homenajeado, sino también un par de clásicos kelsenianos traducidos al español: "Causalidad e imputación", por Ariel Peralta García; ${ }^{44}$ y "La concepción del Estado y la psicología social", por José Melvyn Roig Blakey y Ariel Peralta García. ${ }^{65}$

Por el otro, el segundo incorporó artículos de Agustín Pérez Carrillo ${ }^{66}$ y de Roberto J. Vernengo, ${ }^{67}$ incluido un texto de H.L.A. Hart ${ }^{68}$ y varios clásicos kelsenianos traducidos al español: "Sobre el concepto de norma", por Javier Esqui vel; 69 "El principio de igualdad de soberanía entre los Estados como base de la organización internacional", por Enrique Ferrer Vieyra;70 "Teoría del derecho internacional con-

61 Vid. Esquivel, Javier, "El modelo kelseniano", en loc. cit. en la nota 59, pp. 25-33.

62 Vid. Recaséns Siches, Luis, "Balance de la Teoría Pura del Derecho de Kelsen”, en loc. cit. en la nota 59, pp. 165-177.

63 Vid. Tamayo y Salmorán, Rolando, "Los sistemas jurídicos y sus criterios de identidad. (Ensayo)", en loc. cit. en la nota 59, pp. 179-204.

64 Vid. Kelsen, Hans, "Causalidad e imputación", trad. de Ariel Peralta García, en loc. cit. en la nota 59, pp. 207-232.

65 Vid. Kelsen, H., "La concepción del Estado y la psicología social. Con referencia especial a la teoría del grupo, de Freud", trad. de José Melvyn Roig Blakey y Ariel Peralta García, en loc. cit. en la nota 59, pp. 233-267.

66 Vid. Pérez Carrillo, Agustín, "La definición legal", en loc. cit. en la nota 60, pp. 155-168.

67 Vid. Vernengo, Roberto J., "Norma jurídica y esquema referencial”, en loc. cit. en la nota 60, pp. 189-198.

68 Vid. Hart, H. L. A., "Teoría de Kelsen sobre la unidad del derecho", en loc. cit. en la nota 60, pp. 105-140.

69 Vid. Kelsen, Hans, "Sobre el concepto de norma", trad. de Javier Esquivel, en loc. cit. en la nota 60, pp. 201-213.

70 Vid. Kelsen, Hans, "El principio de igualdad de soberanía entre los Estados como base de la organización internacional", trad. de Enrique Ferrer Vieyra, en loc. cit. en la nota 60, pp. 215-230. 
Esta revista forma parte del acervo de la Biblioteca Jurídica Virtual del Instituto de Investigaciones Jurídicas de la UNAM www.juridicas.unam.mx

http://biblio.juridicas.unam.mx

IMER B. FLORES

suetudinario", por Ariel Peralta Garcia;71 "Derogación”72 y "Derecho y lógica", 73 ambos por Alfonso Ortiz.

Cabe señalar que en ese mismo año apareció publicado en la Revista de la Facultad de Derecho de México "Un documento poco conocido de Kelsen". ${ }^{74}$ Dicho documento comprende: de un lado, una carta de Gustavo R. Velasco, a la sazón Rector Honorario de la Escuela Libre de Derecho, a Fernando Flores García, Director Técnico de la revista cita$\mathrm{da}$, y una nota preliminar del primero; ${ }^{75} \mathrm{y}$, del otro, un breve intercambio epistolar — traducido al español por el propio Velasco- entre Edmond Cahn y Hans Kelsen, ${ }^{76}$ mismo que el primero publicó, con anuencia del segundo, a manera de reseña bibliográfica de la colección de ensayos What is Justice? Justice, Law and Politics in the Mirror of Science en la New York University Law Review. ${ }^{77}$

Por su parte, tres lustros más tarde, Óscar Correas compiló en 1989 un libro que lleva el sugerente título de El otro $K_{e l s e n}{ }^{78}$ y que integra una serie de artículos de y sobre Kel-

71 Vid. Kelsen, Hans, "Teoría del derecho internacional consuetudinario", trad. de Ariel Peralta García, en loc. cit. en la nota 60, pp. 231-258.

72 Vid. Kelsen, Hans, “Derogación”, trad. Alfonso Ortiz, en loc. cit. en la nota 60, pp. 259-274.

73 Vid. Kelsen, Hans, "Derecho y lógica", trad. Alfonso Ortiz, en loc. cit. en la nota 60, pp. 275-282.

74 Vid. Velasco, Gustavo R., "Un documento poco conocido de Kelsen", Revista de la Facultad de Derecho de México, t. XXIV, núms. 95-96, julio-diciembre de 1974, pp. 769-773.

75 Ibidem, pp. 769-71. En la carta Velasco cuenta incidentalmente: "en septiembre de 1950 fui a la Universidad de Harvard, en donde estaba [Kelsen] como Profesor Visitante. Con algo de dificultad localicé el modesto departamento en que vivía. Me recibió amablemente y a pesar de ser filósofo, le halagó que alguien tuviera el interés de ir a la Universidad y de emplear su tiempo con el objeto de conocerlo".

76 Ibidem, pp. 771-773.

77 Vid. Cahn, Edmond, "What is Justice? Justice, Law and Politics in the Mirror of Science. Book Review", New York University Law Review, vol. 33, No. 7, noviembre de 1958, pp. 1056-1058.

78 Vid. Correas (comp.), op. cit., nota 1.

PROBLEMA

Anuario de Filosofia y Teoría del Derecho, Núm. 8, enero-diciembre de 2014, pp. 53-94 
Esta revista forma parte del acervo de la Biblioteca Jurídica Virtual del Instituto de Investigaciones Jurídicas de la UNAM www.juridicas.unam.mx

http://biblio.juridicas.unam.mx

UNA VISITA A HANS KELSEN EN MÉXICO

sen, más allá de los acostumbrados o tradicionales y que como tales sirven para fundamentar la tesis de la existencia del "otro" Kelsen —o al menos de uno diferente al que normalmente es enseñado. Así, de un lado, incluye artículos de Víctor Alarcón Olguín, ${ }^{79}$ de Ulises Schmill Ordóñez, ${ }^{80}$ y del propio Óscar Correas; ${ }^{81} \mathrm{y}$, del otro lado, incorpora textos en español del mismísimo jefe de la escuela vienesa: "Forma de Estado y visión del mundo", por Gertrudis Payás;82 "Dios y Estado", por Jean Hennequin;83 "El concepto de Estado en la sociología comprensiva", por Ivan Witker; 84 "Acerca de las fronteras entre el método jurídico y el sociológico"; 85 "E1 alma y el derecho", por Teresa Martínez Terán; 86 y "El concepto de Estado y psicología social (teniendo como referencia especial la teoría de las masas según Freud)", por F. Lucce. ${ }^{87}$

79 Vid. Alarcón Olguín, “Hans Kelsen...”, cit., nota 1, pp. 17-26.

80 Vid. Schmill Ordóñez, Ulises, "El concepto de derecho en la teorías de Weber y de Kelsen”, en Correas (comp.), cit., nota 1, pp. 163-93.

81 Vid. Óscar Correas, "El otro Kelsen”, en Correas (comp.), cit., nota 1, pp. 27-55.

82 Vid. Kelsen, Hans, "Forma de Estado y visión del mundo", trad. de Gertrudis Payás, en Correas (comp.), cit. en la nota 1, pp. 223-41.

83 Vid. Kelsen, Hans, "Dios y Estado", trad. de Jean Hennequin, en Correas (comp.), cit., nota 1, pp. 243-66.

84 Vid. Kelsen, Hans, "El concepto de Estado en la sociología comprensiva”, trad. de Ivan Witker, en Correas (comp.), cit., nota 1, pp. 267-81.

85 Vid. Kelsen, Hans, "Acerca de las fronteras entre el método jurídico y el sociológico", en Correas (comp.), cit., nota 1, pp. 283-317. No se indica el nombre del traductor y la traducción no corresponde a la de Leandro Azuara Pérez, cfr. cit. en la nota 35.

86 Vid. Kelsen, Hans, "El alma y el derecho", trad. de Teresa Martínez Terán, en Correas (comp.), cit., nota 1, pp. 319-31.

87 Vid. Kelsen, Hans, "El concepto de Estado y la psicología social. (Teniendo como referencia especial la teoría de las masas según Freud)", trad. de F. Lucce, en Correas (comp.), cit., nota 1, pp. 333-72. 
Esta revista forma parte del acervo de la Biblioteca Jurídica Virtual del Instituto de Investigaciones Jurídicas de la UNAM www.juridicas.unam.mx

http://biblio.juridicas.unam.mx

IMER B. FLORES

Más recientemente, en 2003, aparecieron publicados: por un lado, el libro Ensayos sobre Jurisprudencia y Teologia ${ }^{88}$ que compila algunos trabajos escritos por Kelsen sobre el paralelismo entre las problemáticas de la jurisprudencia (incluida la teoría del Estado) y la teología, así como un estudio sobre las Sagradas Escrituras, el cual comprende varios textos traducidos al español: "Estado y Dios", por Luis Legaz y Lacambra; 89 "La idea de justicia en las Sagradas Escrituras", por Ariel Peralta Garcia;90 "Dios y Estado"91 y "El alma y el derecho", ambos por Ulises Schmill Ordóñez. ${ }^{92}$ Y, por el otro, el libro Ficciones jurídicas, el cual contiene un texto más traducido por Jean Hennequin: "Reflexiones en torno de la teoría de las ficciones jurídicas con especial énfasis en la filosofia del "como si" de Vaihinger". ${ }^{93}$

\section{Polémica en torno a la influencia de Kelsen en México}

Es indudable la gran influencia del pensamiento de Hans Kelsen en México, pero también es innegable que la fidelidad con la que se le presenta deja mucho que desear. Al respecto, Alfonso Noriega Jr. reconoce: ${ }^{94}$

88 Vid. Kelsen, Hans, Ensayos sobre Jurisprudencia y Teología, trad. de Ulises Schmill Ordóñez et al., México, Distribuciones Fontamara, 2003.

89 Vid. Kelsen, Hans, "Estado y Dios", trad. de Luis Legaz y Lacambra, en loc. cit. en la nota 88, pp. 71-80.

90 Vid. Kelsen, Hans, "La idea de justicia en las sagradas escrituras", trad. de Ariel Peralta Garcia, en Ensayos sobre Jurisprudencia y Teología, en loc. cit. en la nota 88, pp. 109-180.

91 Vid. Kelsen, Hans, "Dios y Estado", trad. de Ulises Schmill Ordóñez, en loc. cit. en la nota 88, pp. 43-70.

92 Vid. Kelsen, Hans, "El alma y el derecho", trad. de Ulises Schmill Ordóñez, en loc. cit. en la nota 88, pp. 81-108.

93 Vid. Kelsen, Hans, "Reflexiones en torno de la teoría de las ficciones jurídicas con especial énfasis en la filosofia del "como si" de Vaihinger", trad. de Jean Hennequin, en Hans Kelsen, Lon F. Fuller y Alf Ross, Ficciones jurídicas, México, Distribuciones Fontamara, 2003, pp. 23-56.

94 Noriega Jr., Alfonso, "Palabras preliminares", cit., nota 3, pp. XI-XII.

PROBLEMA

Anuario de Filosofia y Teoría del Derecho, Núm. 8, enero-diciembre de 2014, pp. 53-94 
Esta revista forma parte del acervo de la Biblioteca Jurídica Virtual del Instituto de Investigaciones Jurídicas de la UNAM www.juridicas.unam.mx

http://biblio.juridicas.unam.mx

UNA VISITA A HANS KELSEN EN MÉXICO

E1 Jefe de la Escuela de Viena es uno de los más altos exponentes, si no el primero de ellos, de la ciencia jurídica actual. La originalidad de su doctrina, el rigor de sus desenvolvimientos, la lógica incontestable de sus conclusiones y sobre todo la seriedad y fuerza de sus fundamentos, han hecho que el formalismo jurídico que enseña haya encontrado numerosos adeptos. Podrán discutirse los postulados y las conclusiones de la teoría; podrá diferirse en los puntos de vista adoptados por el maestro vienés, pero es un hecho incuestionable que después de haber sido formulada su Teoria pura del Derecho, nadie puede escapar a su influencia, al menos para refutarla y -lo que es más interesante aúnpara rectificar y reforzar posiciones indudablemente debilitadas por la crítica kelseniana. Kelsen representa hoy día una de esas figuras de valor indudable que marcan jalones en la evolución de la Ciencia del Derecho.

Cierto es que para 1943 era imposible escapar a la influencia de Kelsen, pero claro está que no solamente había adeptos o kelsenianos sino además críticos o anti-kelsenianos. Ahora bien, resulta que efectivamente su pensamiento era enseñado como punto de referencia obligado en las diferentes materias del Plan de Estudios, no sólo en las materias formativas o teóricas desde Introducción al Estudio del Derecho hasta Filosofia del Derecho, incluida Sociología, en general, y Sociología Jurídica, en particular, asi como Teoría (General) del Estado sino también en las informativas o prácticas desde el Derecho Civil hasta el Derecho Penal y del Derecho Constitucional (o Nacional) hasta el Derecho Internacional. Por lo anterior, el pensamiento kelseniano abarcaba prácticamente todo el espectro de los cursos ofrecidos en la carrera de Licenciado en Derecho, pero las más de las veces para sugerir que se le habia no sólo refutado sino también superado al rectificar y reforzar las posturas criticadas. En palabras de Recaséns Siches: ${ }^{95}$

95 Recaséns Siches, Luis, "Prólogo", en Kelsen, Derecho y paz en las relaciones internacionales, cit., nota 35, p. 8. 
En suma: la teoría del Derecho y del Estado, en nuestra época, se ha producido y sigue elaborándose necesariamente en diálogo con Kelsen; pues si las doctrinas de éste no siempre logran adhesión, en todo caso incitan al debate científico, obligando a formular puntos de vista nuevos, que tal vez no se habrian producido sin el concurso del estímulo aportado por Kelsen.

Sin embargo, la cuestión es con qué tanta fidelidad fue su pensamiento comprendido tanto por unos como por otros, pues al parecer en ambos bandos se pecaba ya fuera por exceso al maximizar o por defecto al minimizar sus méritos o deméritos. En palabras de Manuel Echeverría, quien recuerda que Luis Legaz y Lacambra habia dicho que "la filosofia jurídica contemporánea no puede ser sino un diálogo con Hans Kelsen", ${ }^{96}$ el problema es: 97

En México, el diálogo con Hans Kelsen se ha visto dominado por dos actitudes esenciales: la ilimitada adhesión y el rechazo ilimitado. Los grupos confesionales y más reaccionarios han considerado que la teoría pura del derecho constituye un grave ataque a las sagradas instituciones tradicionales del pensamiento jurídico natural. Los grupos de vanguardia ideológica han estimado que el pensamiento jurídico puro es un inútil y frío razonamiento que en nada soluciona las angustias del pueblo y que, más aún, tolera o puede tolerar la fundación de imperios antipopulares.

Esta rivalidad que previsiblemente no pasaría de los argumentos y las refutaciones de cátedra ha llegado, por momentos, a tomar caracteres verdaderamente persecutorios. Se dice que la teoría pura del Derecho es "una fuga ante la vida" (De la Cueva) y que su enseñanza es en extremo peligrosa porque "ataca al derecho natural" (Pallares); pero ni el primer caso se fundamenta el reproche ni en el segundo llega a comprobarse que se trate de un ataque falso.

96 Echeverria, Manuel, Kelsen y los juristas mexicanos, México, UNAM, 1968, p. 28.

97 Ibidem, p. 29. 
Esta revista forma parte del acervo de la Biblioteca Jurídica Virtual del Instituto de Investigaciones Jurídicas de la UNAM www.juridicas.unam.mx

http://biblio.juridicas.unam.mx

UNA VISITA A HANS KELSEN EN MÉXICO

La denuncia de Echeverría a los juristas mexicanos por su relación de amor-odio con Kelsen fue muy elogiada en su momento por Guillermo Héctor Rodríguez, quien en el "Prólogo" que preparó para la misma aplaudía el hecho de que "Por primera vez en la historia de la Universidad Nacional de México, aparece una obra dirigida a denunciar las corrientes ideológicas que anidan en el campo de la jurisprudencia". ${ }^{98}$ Asimismo, explicitaba al escribir el mismo que entendía su papel: "en el sentido de que para el mortecino ambiente científico y técnico-jurídico en que vivimos se requieren varias aclaraciones sin las cuales podrian incrementarse el número de las interpretaciones tendenciosas y de los malentendidos". ${ }^{99}$ Al parecer, Guillermo Héctor Rodríguez tenía en mente la distinción entre las funciones del jurista y del ideólogo:100

La responsabilidad y la pasión del jurista concebido como hombre de ciencia es explicar; en cambio la responsabilidad y la pasión del ideólogo es justificar o bien reprobar y, preferiblemente, justificar de manera absoluta, perfecta, de una vez por todas y para siempre. Para lograr esto no hay vias científicas; solamente hay invocaciones encendidas de fe, inclusive de fe ciega y hasta de carbonero.

Por supuesto que la distinción es análoga a la que Max Weber estableció entre el científico y el político. ${ }^{101}$ En este sentido, está claro que un jurista con pretensiones exclusivamente científicas como Kelsen chocaba de frente con aquellos juristas mexicanos acostumbrados a cumplir con reivindicaciones abiertamente politicas e ideológicas y en cambio era asimilado por quienes querian evitar dichas reivindicaciones.

\footnotetext{
98 Rodríguez, Guillermo Héctor, "Prólogo", en loc. cit. en la nota 96, p. 9.

99 Idem.

100 Ibidem, p. 13.

101 Vid. Weber, Max, El político y el científico, trad. Francisco Rubio Llorente, Madrid, Alianza Editorial, 1967.
} 
Esta revista forma parte del acervo de la Biblioteca Jurídica Virtual del Instituto de Investigaciones Jurídicas de la UNAM www.juridicas.unam.mx

http://biblio.juridicas.unam.mx

IMER B. FLORES

En este orden de ideas, me permito aventurar una hipótesis en el sentido de que dada la pureza metódica kelseniana algunos juristas se sentian amenazados en su quehacer y de ahí buena parte de la resistencia de "los antikelsenianos", sobre todo de los que podemos caracterizar como iusnaturalistas. Sin embargo, la pregunta abierta es: ¿Cuál era la visión que prevalecia? ¿La de los kelsenianos? ¿La de los antikelsenianos? o ¿La de algunos otros? Y, en este último caso: ¿Quiénes eran éstos?

Como es sabido, Kelsen, durante su visita a México, en 1960, tal como recuerda Rabasa: “También hizo, público y privadamente, su reconocimiento por catedráticos que, como los Doctores Eduardo García Máynez y Luis Recaséns Siches, entre otros, estima de excepcional valia". ${ }^{102}$ De esta forma, el hecho de que tratara con tanta cordialidad a sus anfitriones, a quienes consideraba como adversarios más que como enemigos en el campo de las ideas filosófico-jurídicas, propició que algunos pensaran no sólo que tanto García Máynez como Recaséns Siches eran kelsenianos sino además que eran discípulos que habian superado al maestro.

Cabe aclarar que el segundo, después de estudiar con José Ortega y Gasset, tras su paso por las Universidades de Roma y de Berlín, bajo la dirección de Giorgio del Vecchio y de Rudolf Stammler, había sido alumno de Kelsen en la Universidad de Viena, y sería - junto a Justino de Azcarate- su primer traductor; y que el primero quería estudiar con el fundador de la escuela vienesa pero llegó primero a Berlín, donde estudiaría un año con Nicolai Hartmann, y después a Viena, donde encontraría, ya no al jefe, quien para aquel entonces había migrado a la Universidad de Colonia, sino a Alfred Verdross, con quien estudiaría un año. En este sentido, dadas estas influencias no es nada sorprendente que ambos no sólo lo sigan críticamente sino también traten de superarlo al fundar la filosofia del dere-

102 Rabasa, "Prólogo", cit. en la nota 8, p. 9. 
cho sobre la filosofia de los valores de Hartmann o la filosofia de la vida de Ortega y Gasset. 103

Sobre el pensamiento kelseniano, Recaséns Siches advierte: 104

En su teoría pura del Derecho, Kelsen no aborda los problemas estimativos, es decir, no se ocupa de la valoración crítica del Derecho positivo y de los idearios políticos, ni establece criterios ideales; deja completamente aparte este tema y se limita de modo exclusivo y con todo rigor a una teoría lógica pura del Derecho positivo, a una especie de doctrina de la ciencia jurídica, inspirándose en unos supuestos filosóficos neokantianos.

De igual forma, el mismo Recaséns admite en la auto-exposición de su pensamiento: ${ }^{105}$

Aunque... aprendió mucho de esos maestros [Kelsen incluido a la par de del Vecchio y de Stammler], desde el primer momento se dio cuenta que el neo-kantismo, a pesar de sus formidables contribuciones a la Filosofia del Derecho del siglo $\mathrm{XX}$, representaba una dirección ya pasada, que urgentemente debía ser superada...

Así, Recaséns Siches, quien comprendía bien el pensamiento de Kelsen, sería un discípulo crítico del maestro, a

103 Vid. Flores, Imer B., "La filosofia del derecho en México durante el siglo XX”, en García Ramírez, Sergio (coord.), El derecho en México: Dos siglos (1810-2010), t. VIII: Historiografía del derecho, filosofía del derecho y derecho y literatura, México, Porrúa-UNAM, Instituto de Investigaciones Jurídicas, 2010, p. 188. Vid. también Flores, Imer B., "La teoría integral del derecho de Luis Recaséns Siches (1903-1977)”, en Molina Piñeiro, Luis J. et al. (coords.), El pensamiento filosófico-jurídico y politico en Luis Recaséns Siches, México, Porrúa-UNAM, 2003, pp. 54-55; e Flores, Imer B., Eduardo García Máynez (1908-1993): Vida y obra, México, UNAM, Instituto de Investigaciones Jurídicas, 2007, pp. 8-9.

104 Recaséns Siches, Luis, "Prólogo", cit. en la nota 95, p. 10.

105 Recaséns Siches, Luis, Panorama del pensamiento jurídico en el Siglo XX, México, Porrúa, 1963, t. I, p. 489. 
Esta revista forma parte del acervo de la Biblioteca Jurídica Virtual del Instituto de Investigaciones Jurídicas de la UNAM www.juridicas.unam.mx

http://biblio.juridicas.unam.mx

IMER B. FLORES

quien trataria de superar. A grado tal que por su preocupación por los problemas estimativos y con una visión integral del derecho, llegó a acusarlo de haber mutilado a la diosa de la justicia y de dejarla con los muñones ensangrentados con su teoría de la lógica pura al prescindir tanto de la axiología como de la sociología, con lo cual fue fácil de acomodar al lado de los antikelsenianos sin serlo en realidad.

De la misma manera, García Máynez nunca dejó de apuntar y hasta de insistir en la importancia de la teoria pura del derecho de Kelsen, ${ }^{106}$ al grado de ser uno de sus principales expositores y a la vez críticos de la misma. ${ }^{107}$ Es más, el ensayo "Importancia de la teoría jurídica pura" corresponde al texto de las conferencias leídas en la Biblioteca "Antonio Caso" de la Facultad de Derecho de la Universidad Nacional de México, los días 21 y 22 de abril de 1960, tras la visita de Kelsen a México. En palabras de García Máynez: ${ }^{108}$

En los dias inmediatamente anteriores a las vacaciones de Semana Santa la Universidad Nacional de México y su Facultad de Derecho se honraron con la visita del jurista más ilustre de nuestro tiempo. Es posible coincidir o no con sus doctrinas, mas no pasarlas por alto ni dejar de tomar posición ante ellas, sea para difundirlas, para profundizarlas o para oponerse a sus tesis capitales. La prueba está en que ninguna obra seria sobre cualquier gran tema de la teoría jurídica deja nunca, en nuestra época, de considerar el punto de vista del famoso maestro, y en que muchas de esas obras -a menudo las más conspicuas- son o un diálogo con Kelsen o una polémica con él.

De tal suerte, me parece que la visión de Kelsen que prevaleció en principio fue la de García Máynez y de Recaséns

106 Vid. García Máynez, Eduardo, "Importancia de la teoría jurídica pura”, Diánoia. Anuario de Filosofía, año VII, núm. 7, 1961, pp. 3-21.

107 Vid. García Máynez, Eduardo, Algunos aspectos de la doctrina kelseniana. Exposición y crítica, México, Porrúa, 1978.

108 García Máynez, "Importancia...", cit. en la nota 106, p. 3. 
Esta revista forma parte del acervo de la Biblioteca Jurídica Virtual del Instituto de Investigaciones Jurídicas de la UNAM www.juridicas.unam.mx

http://biblio.juridicas.unam.mx

UNA VISITA A HANS KELSEN EN MÉXICO

Siches, quienes no dejaban de reconocer algunos de sus méritos, aunque al tratar de superarlo podían reducir $-\mathrm{O}$ al menos tender a minimizar- los mismos. Es cierto que la visión de los discípulos críticos era compatible con la de los "antikelsenianos" y dejaba mucho que desear para los "kelsenianos".

Al respecto, Rolando Tamayo y Salmorán adelanta —en la "Presentación" que preparó para la publicación en español de la segunda edición de la Reine Rechtslehre- a pesar de que nadie puede ignorar que Kelsen alcanzó una "celebridad insuperada" que lo convirtió en todo un clásico:109

Su obra es continuamente citada, pero en realidad apenas se estudia, apenas se conoce... Su obra es vulgarizada, mal reproducida, se la reduce a una serie de lugares comunes o, en el mejor de los casos, se repiten algunas frases hechas. Esto puede perfectamente verificarse con el hecho de que es la traducción española de la reducida versión francesa de la teoría pura la edición comúnmente manejada.

En este mismo orden de ideas, Ulises Schmill Ordóñez advierte - en la "Introducción" que preparó para la publicación en español de los Hauptprobleme- que para tomar posición respecto a la importante contribución teórica de Kelsen -como ante cualquier otro autor- es necesario adoptar una "actitud crítica": 110

Pero esto implica que debe entenderse la teoría pura del derecho de modo completo y sistemático, de buena fe, sin deformarla, sin imaginarla ni darle una fisonomía que no tiene, hecha al tamaño especial del adversario. Sólo con esta base será posible poner un orden racional y crítico en la rapsodia de teorias jurídicas actuales, que sin conciencia histórica

109 Tamayo y Salmorán, Rolando, "Presentación", en Kelsen, Teoría pura del derecho, cit. en la nota 46, p. 7 (la referencia es omitida.)

110 Schmill Ordóñez, Ulises, "Introducción", en Kelsen, Problemas capitales de la teoría jurídica del Estado..., cit., nota 48, pp. XXXVI-XXXVII. En el original dice "existencia", pero debe decir "exigencia". 
postulan hipótesis específicas para resolver problemas jurídicos particulares, no conectados sistemáticamente en ningún sentido. Uno de los más grandes méritos de la teoría kelseniana es precisamente el hecho de que proporciona un punto de vista unitario y sistemático para la comprensión del derecho, el cual es un objeto muy complejo de estudio y relacionado en muchas y muy diferentes formas con otros objetos de estudio.

Ciertamente nada nuevo se dice cuando se afirma que hay que entender a Kelsen y tomar posición frente a la jurisprudencia pura. Pero a esto hay que agregar la siguiente existencia (sic): las nuevas hipótesis jurisprudenciales que se postulen deben poder resolver los problemas tratados en la teoria pura del derecho y otros nuevos y distintos o, por lo menos, depurar y desarrollar lo que ya se ha logrado. Debe exigirse una conciencia histórica a los investigadores, porque sólo de este modo puede constituirse una ciencia del derecho.

Por su parte, Óscar Correas anota que a la par de "los kelsenistas fieles al espíritu del maestro" había un grupo de "seudokelsenistas" que a partir de la distinción entre descripción y justificación tergiversan el pensamiento filosófico-político de Kelsen "para impedir cualquier discusión - "Sociologizante", le dicen- acerca del contenido del derecho. Y, además, quieren hacer creer que no pronunciarse ¡es una actitud no politica!".111 Del mismo modo, Correas apunta: 112

Con esto, Kelsen se convertía en ese gran jurista, pero también se convertía en un filósofo casi desconocido. De buena o de mala intención - tengo para mí que esto último-, la insistencia de Kelsen en la "pureza" permitió a muchos soslayar el conjunto de su pensamiento, convirtiéndolo en uno de los grandes pero casi desconocidos pensadores políticos del mundo contemporáneo.

111 Correas, Óscar, "Presentación”, en Correas (comp.), cit., nota 1, p. 9.

112 Correas, cit., nota 81, p. 27. 
Esta revista forma parte del acervo de la Biblioteca Jurídica Virtual del Instituto de Investigaciones Jurídicas de la UNAM www.juridicas.unam.mx

http://biblio.juridicas.unam.mx

UNA VISITA A HANS KELSEN EN MÉXICO

Al respecto, Correas ha insistido en la necesidad de enseñar "el otro Kelsen", i.e. el Kelsen de la filosofía política a la par del Kelsen de la "pureza", con lo cual ha dado lugar a la visión no sólo de "los seudokelsenianos" sino también de "los otros", quienes buscan desesperadamente a un Kelsen más integral. ${ }^{113}$

Por tanto, esta(s) visita(s) a Kelsen en México nos dejan como saldo la existencia de cuando menos cinco Hans Kelsen -o mejor dicho de un Hans Kelsen y cuando menos cinco visiones del mismo: 1) la de "los antikelsenianos"; 2) la de "los kelsenianos"; 3) la de "los discípulos críticos"; 4) la de "los seudokelsenianos"; y 5 la de "los otros". De esta forma, la pregunta está —o sigue- abierta: ¿Cuál es la visión que prevalece?

\section{EPÍlOGO}

Ya para finalizar nos gustaría reproducir un par de anécdotas de Kelsen, para ejemplificar la agudeza de su pensar y la trascendencia de su obra, por la cual tiene reservado un lugar en la historia universal como parte de la aristocracia de nuestro intelecto.

Por una parte, Emilio O. Rabasa en el marco de la célebre visita de 1960:114

Recuerdo que desde la Torre de Humanidades de la Ciudad Universitaria, a donde habíamos acudido por insistencia de Kelsen de dialogar con el eminente maestro mexicano, también filósofo del Derecho, Dr. Eduardo García Máynez, tuve oportunidad de explicarle desde las alturas de esa Torre de Humanidades la disposición de las diferentes escuelas y facultades que circundan el Campus Universitario.

Desde nuestro punto de observación lo más próximo era la Facultad de Filosofia, seguida por la Facultad de Derecho y luego la de Economía. Ese orden arquitectónico, comentó

113 Ibidem, pp. 27-55.

114 Rabasa, "Nota liminar...", cit., nota 7, pp. 14-15. 
Esta revista forma parte del acervo de la Biblioteca Jurídica Virtual del Instituto de Investigaciones Jurídicas de la UNAM www.juridicas.unam.mx

http://biblio.juridicas.unam.mx

IMER B. FLORES

Kelsen, corresponde a la realidad: la Filosofia como sustento, el Derecho como norma y la Economía como realización concreta.

Por otra parte, Rolando Tamayo y Salmorán tras la muerte de Kelsen narra un pasaje de su vida:115

Cuenta el profesor Rudolf Metal que enseñando en Ginebra Kelsen tuvo noticia de que había olvidado su nombre y se disculpó diciéndole al alumno: "Por favor perdone que no le llame por su nombre. Tengo muy mala memoria para los nombres y temo que un dia, al despertarme, no pueda recordar el mío". El estudiante, un joven francés, lo saludó cortésmente y replicó: "Mon Cher maître, quizás pueda usted no recordar su nombre, pero la historia universal nunca lo olvidará".

\section{REFERENCIAS}

AladÁr MÉTAll, Rudolf, Hans Kelsen, Vida y obra, trad. de Javier Esquivel, México, UNAM, Instituto de Investigaciones Jurídicas, 1976.

AlARCón, Alicia, El Consejo Universitario. Sesiones de 1924-1977, México, UNAM, t. I, 1979.

Alarcón Olguín, Víctor, "Hans Kelsen: Bitácora de un itinerante”, en CORREAS, Óscar (comp.), El otro Kelsen, México, UNAM, 1989.

BAYER, Kurt G. "Hans Kelsen. Vida y obra", Revista de la Facultad de Derecho, t. LV, núm. 244, 2005.

CAHN, Edmond, "What is Justice? Justice, Law and Politics in the Mirror of Science. Book Review", New York University Law Review, Vol. 33, No. 7, November, 1958.

"Cartas del doctor Hans Kelsen", Revista de la Facultad de Derecho de México, t. XXII, núms. 87-88, julio-diciembre de 1972.

115 Tamayo y Salmorán, "Hans Kelsen...", cit., nota 6, p. XV. 
Esta revista forma parte del acervo de la Biblioteca Jurídica Virtual del Instituto de Investigaciones Jurídicas de la UNAM www.juridicas.unam.mx

http://biblio.juridicas.unam.mx

UNA VISITA A HANS KELSEN EN MÉXICO

CORREAS, Óscar, "Presentación”, en CORREAS, Óscar (comp.), El otro Kelsen, México, UNAM, 1989.

ECHEVERRÍA, Manuel, Kelsen y los juristas mexicanos, México, UNAM, 1968.

ESQUIVEL, Javier, "El modelo kelseniano", Boletín Mexicano de Derecho Comparado, nueva serie, año VII, núm. 19, enero-abril de 1974.

FlORES, Imer B., Eduardo García Máynez (1908-1993): vida y obra, México, UNAM, Instituto de Investigaciones Jurídicas, 2007.

FLORES, Imer B., "La filosofia del derecho en México durante el siglo XX", en GARCía RAMíREZ, Sergio (coord.), $E l$ derecho en México: Dos siglos (1810-2010), t. VIII: Historiografía del derecho, filosofía del derecho y derecho y literatura, México, Porrúa-UNAM, Instituto de Investigaciones Jurídicas, 2010.

FloRES, Imer B., "La teoría integral del derecho de Luis Recaséns Siches (1903-1977)", en MOLINA PIÑEIRO, Luis J. et al. (coords.), El pensamiento filosófico-jurídico y político en Luis Recaséns Siches, México, Porrúa-UNAM, 2003.

GARCÍA MÁYNEZ, Eduardo, Algunos aspectos de la doctrina kelseniana. Exposición y crítica, México, Porrúa, 1978.

GARCÍA MÁYNEZ, Eduardo, "Importancia de la teoría jurídica pura", Diánoia. Anuario de Filosofía, año VII, núm. 7, 1961.

GRANT, J. A. C., "Semblanza", trad. de Guadalupe Ordóñez, Boletin Mexicano de Derecho Comparado, nueva serie, año VII, núm. 21, septiembre-diciembre de 1974.

HART, H. L. A., "Teoría de Kelsen sobre la unidad del derecho", Boletín Mexicano de Derecho Comparado, nueva serie, año VII, núm. 21, septiembre-diciembre de 1974. 
Esta revista forma parte del acervo de la Biblioteca Jurídica Virtual del Instituto de Investigaciones Jurídicas de la UNAM www.juridicas.unam.mx

http://biblio.juridicas.unam.mx

IMER B. FLORES

"Homenaje al profesor Hans Kelsen", Revista de la Facultad de Derecho de México, t. XXII, núms. 85-86, enero-junio de 1972.

KELSEN, Hans, "Acerca de las fronteras entre el método jurídico y el sociológico", en CORREAS, Óscar (comp.), El otro Kelsen, México, UNAM, 1989.

KELSEN, Hans, "Causalidad e imputación", trad. Ariel Peralta García, Boletin Mexicano de Derecho Comparado, nueva serie, año VII, núm. 19, enero-abril de 1974.

Kelsen, Hans, Compendio de Teoría General del Estado, trad. de Luis Recaséns Siches y Justino de Azcárate, México, Editora Nacional, 1980.

Kelsen, Hans, Contribuciones a la Teoria Pura del Derecho, trad. de Eduardo A. Vásquez, México, Distribuciones Fontamara, 1991.

KELSEN, Hans, "Derecho y lógica", Cuadernos de Crítica, núm. 6, México, UNAM, Instituto de Investigaciones Filosóficas, 1978.

KELSEn, Hans, "Derecho y lógica", trad. de Alfonso Ortiz, Boletin Mexicano de Derecho Comparado, nueva serie, año VII, núm. 21, septiembre-diciembre de 1974.

KELSEN, Hans, Derecho y paz en las relaciones internacionales, trad. de Florencio Acosta, México, Fondo de Cultura Económica, 1943.

KELSEN, Hans, "Derogación", trad. de Alfonso Ortiz, Boletín Mexicano de Derecho Comparado, nueva serie, año VII, núm. 21, septiembre-diciembre de 1974.

Kelsen, Hans, "Dios y Estado", trad. de Jean Hennequin, en CorReas, Óscar (comp.), El otro Kelsen, México, UNAM, 1989.

KELSEN, Hans, "Dios y Estado", trad. de Ulises Schmill Ordóñez, en Ensayos sobre jurisprudencia y teología, trad. de Ulises Schmill Ordóñez et al., México, Distribuciones Fontamara, 2003. 
Esta revista forma parte del acervo de la Biblioteca Jurídica Virtual del Instituto de Investigaciones Jurídicas de la UNAM www.juridicas.unam.mx

http://biblio.juridicas.unam.mx

UNA VISITA A HANS KELSEN EN MÉXICO

KELSEN, Hans, "El alma y el derecho", trad. de Teresa Martínez Terán, en CORREAS, Óscar (comp.), El otro Kelsen, México, UNAM, 1989.

KELSEN, Hans, "El alma y el derecho", trad. de Ulises Schmill Ordóñez, en Ensayos sobre jurisprudencia y teología, trad. de Ulises Schmill Ordóñez et al., México, Distribuciones Fontamara, 2003.

KELSEN, Hans, "El concepto de Estado en la sociología comprensiva", trad. Ivan Witker, en CORREAS, Óscar (comp.), El otro Kelsen, México, UNAM, 1989.

KELSEN, Hans, "El concepto de Estado y la psicología social. (Teniendo como referencia especial la teoría de las masas según Freud)", trad. de F. Lucce, en CORREAS, Óscar (comp.), El otro Kelsen, México, UNAM, 1989.

KELSEn, Hans, El contrato y el tratado. Analizados desde el punto de vista de la Teoría Pura del Derecho, trad. de Eduardo García Máynez, México, Imprenta Universitaria, 1943.

KELSEN, Hans, "El principio de igualdad de soberanía entre los Estados como base de la organización internacional", trad. de Enrique Ferrer Vieyra, La justicia, año XVI, t. XVI, núm. 223, marzo de 1946.

KELSEN, Hans, "El principio de igualdad de soberanía entre los Estados como base de la organización internacional", trad. de Enrique Ferrer Vieyra, Boletin Mexicano de Derecho Comparado, nueva serie, año VII, núm. 21, septiembre-diciembre de 1974.

KELSEN, Hans, Ensayos sobre jurisprudencia y teología, trad. de Ulises Schmill Ordóñez et al., México, Distribuciones Fontamara, 2003.

Kelsen, Hans, Esencia y valor de la democracia, trad. de Luis Luengo Tapia y Luis Legaz y Lacambra, México, Editora Nacional, 1974.

KELSEN, Hans, "Estado y Dios", trad. de Luis Legaz y Lacambra, en Ensayos sobre jurisprudencia y teologia, trad. de Ulises Schmill Ordóñez et al., México, Distribuciones Fontamara, 2003. 
Esta revista forma parte del acervo de la Biblioteca Jurídica Virtual del Instituto de Investigaciones Jurídicas de la UNAM www.juridicas.unam.mx

http://biblio.juridicas.unam.mx

IMER B. FLORES

KELSEN, Hans, "Forma de Estado y visión del mundo", trad. Gertrudis Payás, en CORREAS, Óscar (comp.), El otro Kelsen, México, UNAM, 1989.

Kelsen, Hans, Introducción a la Teoría Pura del Derecho, trad. de Emilio O. Rabasa, México, UNAM, Facultad de Derecho, 1960.

KELSEN, Hans, "La concepción del Estado y la psicología social. Con referencia especial a la teoria del grupo, de Freud", trad. de José Melvyn Roig Blakey y Ariel Peralta García, Boletín Mexicano de Derecho Comparado, nueva serie, año VII, núm. 19, enero-abril de 1974.

KELSEN, Hans, "La fundamentación de la doctrina del derecho natural", trad. de Federico Weber, Juridica. Anuario del Departamento de Derecho de la Universidad Iberoamericana, t. II, núm. 2, 1970.

KELSEN, Hans, "La garantía jurisdiccional de la constitución. (La justicia constitucional)", trad. de Rolando Tamayo y Salmorán, Anuario Jurídico, núm. 1, 1974.

KELSEN, Hans, "La idea de justicia en las sagradas escrituras", trad. de Ariel Peralta García, en Ensayos sobre jurisprudencia y teologia, trad. de Ulises Schmill Ordóñez et al., México, Distribuciones Fontamara, 2003.

KELSEN, Hans, La idea del derecho natural y otros ensayos, trad. de Francisco Ayala et al., México, Editora Nacional, 1974.

KELSEN, Hans, "Las metamorfosis de la idea de justicia", trad. de Óscar Morineau, Revista de la Escuela Nacional de Jurisprudencia, t. XI, núm. 44, octubre-diciembre de 1949.

Kelsen, Hans, Problemas capitales de la teoria juridica del Estado. (Desarrollados con base en la doctrina de la proposición jurídica), trad. de Wenceslao Roces, México, Porrúa-UNAM, Instituto de Investigaciones Jurídicas, 1987. 
Esta revista forma parte del acervo de la Biblioteca Jurídica Virtual del Instituto de Investigaciones Jurídicas de la UNAM www.juridicas.unam.mx

http://biblio.juridicas.unam.mx

UNA VISITA A HANS KELSEN EN MÉXICO

KELSEN, Hans, “¿Qué es el positivismo jurídico?”, trad. de Mario de la Cueva, Revista de la Facultad de Derecho de México, t. XVI, núm. 61, enero-marzo de 1966.

KELSEN, Hans, ¿Qué es la justicia?, trad. de Ernesto Garzón Valdés, México, Distribuciones Fontamara, 1991.

KELSEn, Hans, ¿Qué es la Teoría Pura del Derecho?, trad. de Ernesto Garzón Valdés, México, Distribuciones Fontamara, 1991.

KELSEN, Hans, "Qué es un acto jurídico?", trad. de Ulises Schmill Ordóñez, Isonomía. Revista de Teoría y Filosofía del Derecho, núm. 4, abril de 1996.

KELSEN, Hans, "Reflexiones en torno de la teoría de las ficciones jurídicas con especial énfasis en la filosofia del "como si" de Vaihinger", trad. de Jean Hennequin, en Kelsen, Hans, Fuller, Lon F. y Ross, Alf, Ficciones jurídicas, México, Distribuciones Fontamara, 2003.

KELSEN, Hans, "Sobre el concepto de norma", trad. de Javier Esquivel, Boletín Mexicano de Derecho Comparado, nueva serie, año VII, núm. 21, septiembre-diciembre de 1974.

KELSEN, Hans, "Sobre los límites entre el método sociológico y el jurídico", trad. de Leandro Azuara Pérez, Revista de la Facultad de Derecho de México, t. XIX, núms. 75-76, julio-diciembre de 1969.

KELSEn, Hans, Socialismo y Estado (Una investigación sobre la teoría politica del marxismo), trad. de Alfonso García Ruíz, México, Siglo XXI Editores, 1982.

KELSEN, Hans, "Teoria del derecho internacional consuetudinario", trad. de Ariel Peralta Garcia, Boletin Mexicano de Derecho Comparado, nueva serie, año VII, núm. 21, septiembre-diciembre de 1974.

KELSEN, Hans, Teoría general del derecho y del Estado, trad. de Eduardo García Máynez, México, Imprenta Universitaria, 1949. 
Esta revista forma parte del acervo de la Biblioteca Jurídica Virtual del Instituto de Investigaciones Jurídicas de la UNAM www.juridicas.unam.mx

http://biblio.juridicas.unam.mx

IMER B. FLORES

KELSEN, Hans, Teoria General del Estado, trad. de Luis Legaz y Lacambra, México, Editora Nacional, 1965.

KELSEn, Hans, Teoría pura del derecho, trad. de Roberto J. Vernengo, México, UNAM, 1979.

KELSEn, Hans, La Teoría Pura del Derecho. Introducción a la problemática científica del derecho, trad. de Jorge G. Tejerina, México, Editora Nacional, 1981.

KElsen, Hans, La Teoría Pura del Derecho. Método y conceptos fundamentales, trad. de Luis Legaz y Lacambra, México, Colofón, 1989.

KELSEn, Hans, Teoría general de las normas, trad. de Hugo Carlos Delory Jacobs, México, Trillas, 1994.

KELSEN, Hans, "Teoría pura y teoría egológica. Respuesta al artículo de Carlos Cossio: Teoría Egológica y Teoría Pura (Balance provisional de la visita de Kelsen a la Argentina)", trad. de Eduardo García Máynez, Revista de la Facultad de Derecho de México, t. III, núm. 10, abril-junio de 1953.

PÉrez CARrillo, Agustín "La definición legal", Boletín Mexicano de Derecho Comparado, nueva serie, año VII, núm. 21, septiembre-diciembre de 1974.

"Próximos cursos de invierno en los meses de enero y febrero de 1947", Revista de la Escuela Nacional de Jurisprudencia, t. VIII, núm. 32, octubre-diciembre de 1946.

RABASA, Emilio O., "Nota liminar a la segunda edición peruana", en Kelsen, Hans, Introducción a la Teoría Pura del Derecho, trad. de Emilio O. Rabasa, Lima, Asociación Peruana de Derecho Constitucional, 2001.

RABASA, Emilio O., "Prólogo", en Kelsen, Hans, Introducción a la Teoría Pura del Derecho, trad. de Emilio O. Rabasa, México, UNAM, Facultad de Derecho, 1960.

ReCAsÉns Siches, Luis, "Balance de la Teoría Pura del Derecho de Kelsen", Boletín Mexicano de Derecho Comparado, nueva serie, año VII, núm. 19, enero-abril de 1974. 
Esta revista forma parte del acervo de la Biblioteca Jurídica Virtual del Instituto de Investigaciones Jurídicas de la UNAM www.juridicas.unam.mx

http://biblio.juridicas.unam.mx

UNA VISITA A HANS KELSEN EN MÉXICO

RECASÉns Siches, Luis, Panorama del pensamiento jurídico en el Siglo XX, México, Porrúa, t. I, 1963.

RECASÉns Siches, Luis, "Prólogo", en Kelsen, Hans, Derecho y paz en las relaciones internacionales, trad. de Florencio Acosta, México, Fondo de Cultura Económica, 1943.

RodRíguez GuILlermo, Héctor, "Prólogo", en Echeverría, Manuel, Kelsen y los juristas mexicanos, México, UNAM, 1968.

SCHMILL ORDÓÑEZ, Ulises, "El concepto de derecho en la teorias de Weber y de Kelsen", en CORREAS, Óscar (comp.), El otro Kelsen, México, UNAM, 1989.

SCHMILL ORDÓÑEZ, Ulises, "Introducción", Problemas capitales de la teoría jurídica del Estado. (Desarrollados con base en la doctrina de la proposición juridica), trad. de Wenceslao Roces, México, Porrúa-UNAM, Instituto de Investigaciones Jurídicas, 1987.

SCHMILl ORDÓÑEZ, Ulises, "Un poema de Hans Kelsen", Doxa. Cuadernos de Filosofía del Derecho, núm. 19, 1996.

TAMAYO Y SALMORÁN, Rolando, "Estudios en memoria de Hans Kelsen", Boletin Mexicano de Derecho Comparado, nueva serie, año VII, núm. 19, enero-abril de 1974.

TAMAYO Y SALMORÁn, Rolando, "Estudios en memoria de Hans Kelsen", Boletin Mexicano de Derecho Comparado, nueva serie, año VII, núm. 21, septiembre-diciembre de 1974.

TAMAYO Y SALMORÁN, Rolando, "Los sistemas jurídicos y sus criterios de identidad. (Ensayo)", en SALMORÁN, Rolando, "Hans Kelsen. In memoriam", Boletín Mexicano de Derecho Comparado, año VII, núm. 19, enero-abril de 1974.

TAMAYO Y SAlmorÁn, Rolando, "Presentación", en Kelsen, Hans, Teoría Pura del Derecho, trad. de Roberto J. Vernengo, México, UNAM, 1979. 
Esta revista forma parte del acervo de la Biblioteca Jurídica Virtual del Instituto de Investigaciones Jurídicas de la UNAM

VELASCO, Gustavo R., "Un documento poco conocido de Kelsen", Revista de la Facultad de Derecho de México, t. XXIV, núms. 95-96, julio-diciembre de 1974.

VERNENGO, Roberto J., "Norma jurídica y esquema referencial", Boletín Mexicano de Derecho Comparado, nueva serie, año VII, núm. 21, septiembre-diciembre de 1974.

WEBER, Max, El politico y el científico, trad. de Francisco Rubio Llorente, Madrid, Alianza Editorial, 1967. 